Motrivivência $\quad$ v. 26 , n. 42, p. 222-237, junho/2014

http://dx.doi.org/10.5007/2175-8042.2014v26n42p222

\title{
AS DIRETRIZES DO NASF E A PRESENÇA DO PROFISSIONAL EM EDUCAÇÃO FÍSICA
}

\author{
Jessica Félix Nicácio Martinez' \\ Ana Márcia Silva² \\ Maria Sebastiana Silva ${ }^{3}$
}

\section{RESUMO}

Texto que discute a participação do profissional em Educação Física no programa Núcleo de Apoio à Saúde da Família (NASF), com enfoque na cidade de Goiânia (Brasil). Estudo de metodologia de revisão bibliográfica e documental que encontrou os seguintes resultados: a presença desse profissional em 49,2\% das equipes do NASF no Brasil; uma diversidade de denominações para o profissional; e no caso de Goiânia (Brasil), os profissionais atuantes recebem menor remuneração que os demais profissionais da equipe multidisciplinar de saúde, apesar de terem uma valoração bastante positiva de seu trabalho por parte dos demais profissionais, assim como da gestão.

Palavras-chave: Saúde Pública; Núcleo de Apoio à Saúde da Família; Educação Física.

1 Doutoranda em Ciências da Saúde. Professora da Faculdade de Educação Física da UFG, Goiás, Brasil. E-mail: jessicafelix01@yahoo.com.br

2 Doutora em Ciências Humanas. Professora da Faculdade de Educação Física da UFG, Goiás, Brasil.

E-mail: anamarcia@pq.cnpq.br

3 Doutora em Nutrição. Professora da Faculdade de Educação Física da UFG, Goiás, Brasil.

E-mail: maria2593857@hotmail.com 


\section{INTRODUÇÃO}

Em 2008, o Ministério da Saúde publica portaria que institui o programa Núcleo de Apoio à Saúde da Família (NASF) (BRASIL, 2008) e na sequência torna público o documento intitulado de Diretrizes do NASF (BRASIL, 2009), atualizando-o posteriormente com uma redefinição de parâmetros e modalidades (BRASIL, 2012). Embora este não seja o primeiro documento a balizar as atividades que podem vir a ser desenvolvidas pelo profissional de Educação Física, é o texto oficial que vai sistematizar reflexões em torno do trabalho específico desse profissional no âmbito da saúde pública brasileira, formalizada no referido programa.

Considerando esses elementos e a recente presença da Educação Física no Sistema Público de Saúde é que se desenvolveu este estudo de metodologia de revisão bibliográfica e documental. Objetivou-se neste texto, destacar os conceitos e princípios centrais das diretrizes que orientam o trabalho no NASF e estabelecer um diálogo com outras produções acadêmicas e reflexões que tratam da temática no campo da Educação Física. Objetivou-se, também, fazer uma análise dos dados da presença do profissional de Educação Física nos NASFs brasileiros, com foco sobre processo de implantação do NASF na cidade de Goiânia (Brasil) em seus desafios iniciais e conformação do corpo de profissionais do campo que dele participam.

Os procedimentos metodológicos seguiram as orientações da técnica de Análise Temática, a qual segundo Minayo (2010) é uma das mais adequadas formas de investigação qualitativa do material sobre saúde. Essa técnica foi organizada em três momentos: i) pré-análise - nesta fase, selecionamos os documentos oficiais que tratam da Educação Física no NASF e as produções acadêmicas sobre o tema nas principais bases de dados do campo da saúde e da Educação Física. As produções foram selecionadas a partir das seguintes palavras-chaves: atividade física, exercício físico, práticas corporais e Educação Física e seus diferentes intercruzamentos com saúde pública, saúde coletiva, Sistema Único de Saúde (SUS) e serviço público de saúde. Selecionamos aquelas produções acadêmicas que possuíam relação direta com a reflexão sobre a Educação Física no NASF. Após essa seleção inicial, estabelecemos um contato exaustivo com o conteúdo analisado, considerando as normas de validade qualitativa (exaustividade, representatividade, homogeneidade e pertinência) e buscando responder às indagações iniciais; ii) exploração do material - nesta fase, ocorreu a operação de codificação propriamente dita, na qual buscamos "reduzir" o material analisado às suas expressões significativas. As unidades de registro e contexto foram recortadas do material para, em seguida, serem visualizadas com mais clareza em sua repetição e significado. No final, foi realizado um processo de classificação elencando as categorias empíricas e/ou teóricas advindas da análise, e, iii) tratamento e interpretação dos resultados obtidos - buscamos compreender o significado das informações obtidas por meio da presença ou freqüência de núcleos de sentido. Retornou-se às questões e objetivos da pesquisa em um processo dialético de (re)construção do material empírico coletado com novas mediações (MINAYO, 2010). 
Um perfil do profissional de Educação Física no NASF no Brasil

Em pesquisa sobre a inserção do profissional de Educação Física no NASF, Santos (2012) observou que esse profissional está presente em média em 49,2\% das equipes no Brasil. Identificou, também, diferenças expressivas entre as regiões do Brasil, chegando a percentuais superiores a $75 \%$ nos Estados do Acre e Paraná e nenhum no Distrito Federal. Contudo, há uma baixa representatividade profissional quanto à cobertura da população pela estratégia da Saúde da Família, não chegando a um profissional por 100.000 habitantes. Apesar disso, os dados indicam que o profissional de Educação Física encontra-se entre as cinco profissões mais contratadas para trabalhar no NASF.

Dados de 2013 do Ministério da Saúde ${ }^{4}$ apontam que há 1031 profissionais de Educação Física trabalhando no NASF em todo o país e continua sendo uma das cinco profissões mais contratadas para atuar nesse programa.

No quadro abaixo estão apresentados os dados atuais do percentual de profissionais que compõem o NASF nas suas duas modalidades no país:

Quadro 1: Distribuição dos profissionais que trabalham no NASF.

\begin{tabular}{|l|c|c|}
\hline Profissionais & $\begin{array}{c}\text { \% NASF I com profissional } \\
\text { na equipe }\end{array}$ & $\begin{array}{c}\text { \% NASF II com profissional } \\
\text { na equipe }\end{array}$ \\
\hline Fisioterapeuta Geral & $86,0 \%$ & $75,4 \%$ \\
\hline Psicólogo Clínico & $85,5 \%$ & $77,1 \%$ \\
\hline Nutricionista & $79,9 \%$ & $60,9 \%$ \\
\hline Assistente social & $67,9 \%$ & $42,5 \%$ \\
\hline Fonoaudiólogo & $47,3 \%$ & $24,8 \%$ \\
\hline $\begin{array}{l}\text { Profissional de Educação Física na } \\
\text { saúde }\end{array}$ & $41,7 \%$ & $17,8 \%$ \\
\hline Farmacêutico & $41,1 \%$ & $20,8 \%$ \\
\hline Avaliador Físico & $7,6 \%$ & $10,8 \%$ \\
\hline
\end{tabular}

Fonte: Ministério da Saúde (2013).

Como identificamos no quadro acima, há duas denominações diferentes para um profissional que deve ter formação em nível superior no campo da Educação Física. Este dado nos estimulou a dar maior visibilidade às diversas denominações que estão sendo utilizadas no NASF fornecendo um panorama mais completo da questão. Abaixo, apresentamos em forma de quadro as diversas denominações utilizadas para o registro do profissional de Educação Física no NASF.

4 Os dados apresentados foram sistematizados e gentilmente cedidos às pesquisadoras pela Coordenação Geral de Gestão da Atenção Básica (Departamento de Atenção Básica/Secretaria de Atenção à Saúde/Ministério da Saúde) em Junho de 2013. 
Quadro 2: Denominações Profissionais para o campo da Educação Física no NASF.

\begin{tabular}{|l|c|}
\hline Denominação & Número absoluto \\
\hline Profissional de EF na saúde & 762 \\
\hline Avaliador Físico & 183 \\
\hline Preparador Físico & 38 \\
\hline Professor de EF no Ensino Superior & 25 \\
\hline Professor de EF no Ensino Médio & 12 \\
\hline Técnico de desporto individual e coletivo (exceto futebol) & 08 \\
\hline Ludomotricista & 03 \\
\hline
\end{tabular}

Fonte: Brasil (2013).

As diferentes formas de registrar o profissional de Educação Física na criação do NASF em 2008 indicavam as tensões quanto à centralidade do trabalho deste profissional na saúde. Importante lembrar que, segundo a Classificação Brasileira de Ocupação (CBO), os profissionais de Educação Física no NASF podem ser cadastrados como: avaliador físico; ludomotricista; preparador de atleta; preparador físico; técnico de desporto individual e coletivo (exceto futebol); técnico de laboratório e fiscalização desportiva (BRASIL, 2008).

Segundo as elaborações de Bueno (2012), essas definições tiveram interferência do Conselho Federal de Educação Física quando ocorreu a atualização da CBO em 2002. A autora também argumenta que após a criação do NASF não é possível cadastrar os profissionais como "professor de Educação Física no ensino superior" ou "professor de Educação Física no ensino médio". Essas CBOs eram vinculadas à educação, sendo as únicas formas de registro da Educação Física antes da atualização da CBO. Ademais, a autora ressalta que os procedimentos vinculados à $\mathrm{CBO}$ "professor de Educação Física no ensino superior" estão muito mais condizentes com o trabalho desenvolvido por esse profissional na saúde pública, por exemplo, possibilitando o cadastro em atividade educativa/orientação em grupo e visita domiciliar. Frente a esta situação e, talvez, como uma busca por superar essa fragmentação da Educação Física, foi publicada a portaria $\mathrm{n}^{\circ} 256$, em 11 de março de 2013, criando a CBO provisória 2241E1 de "profissional de educação física na saúde".

Sobre o perfil desses profissionais que estão atuando no NASF em todo país, os dados de pesquisa realizada por Santos (2012) são expressivos. Foram entrevistados por telefone 296 profissionais de Educação Física que trabalham no NASF em todo o país. Na entrevista foram consideradas as condições de trabalho, formação profissional e atividades desenvolvidas. Os resultados indicam que há predominância do gênero masculino $(53,4 \%)$, com média de idade de 32,3 anos $( \pm 7,4)$. A grande maioria $(74,7 \%)$ possui formação em licenciatura plena, sendo que $55,1 \%$ realizaram seu processo formativo em instituições particulares de ensino. A maioria dos entrevistados $(55,7 \%)$ possui pós-graduação em Educação Física e Saúde.

Em se tratando de informações relativas às condições de trabalho, a mesma 
pesquisadora identificou que há prevalência de trabalho com carga horária de 40 horas semanais, contudo $11,5 \%$ relataram carga horária inferior. No entanto, 76,4\% possuem vínculo empregatício precarizado, especialmente pela flexibilidade da forma de contratação dos profissionais, e apenas 23,6\% são estáveis. Ademais, 57,8\% dos entrevistados possuíam outro vínculo profissional. A maioria dos profissionais relatou não possuir condições mínimas para o trabalho $(56,4 \%)$, quando considerados os recursos materiais e estrutura física; informaram, no entanto, que houve capacitação pedagógica e avaliação da gestão municipal $(75,7 \%)$ (SANTOS, 2012).

Na pesquisa de Mendonça (2012), identificou-se a importância do vínculo empregatício para a continuidade do trabaIho, qualidade das atividades e saúde dos profissionais. No caso dos trabalhadores de Educação Física do NASF de Londrina/ $\mathrm{PR}$, investigou-se que os mesmos tinham um contrato emergencial de 60 dias e uma jornada de trabalho de 40 horas. O autor salienta que esse tipo de contratação ocorreu porque uma Organização da Sociedade Civil de Interesse Público (OSCIP), a qual era responsável pelas contratações dos profissionais de saúde, estava envolvida com denúncias de corrupção, o que resultou em rompimento de contrato com o município e insegurança para os trabalhadores. Além disso, seis dos dez profissionais de Educação Física do NASF de Londrina/PR investigados tinham dupla jornada de trabalho exercendo outra atividade remunerada, em geral, em empresas privadas.

De forma similar, no município do Rio de Janeiro, os pesquisadores analisaram que o processo de contratação de profissionais de Educação Física não foi transparente ou pública. A responsabilidade pelas contratações é das Organizações Sociais, as quais são instituídas por área programática, com diferenças nos processos de seleção e contratação de profissionais (XAVIER; ESPÍRITO-SANTO, 2011).

Apesar das poucas investigações sobre a implantação do NASF no país, chama atenção o processo de precarização e flexibilização do trabalho a partir da contratação dos profissionais por Organizações Sociais, a qual camufla a privatização do setor, como indicam as elaborações de Pinto (2000). Ademais, em um clima de insegurança no trabalho, os profissionais acabam buscando outros vínculos empregatícios, fato que gera sobrecarga de trabalho e dificuldades na construção de projetos mais permanentes e adequados aos fins propostos. Esses elementos parecem ser fundamentais para considerarmos as determinações estruturais que impactam no trabalho, reflexões necessárias sobre a função social da Educação Física na Saúde Pública.

\section{As diretrizes do NASF e o trabalho dos profissionais de Educação Física}

Para Pedrosa e Leal (2012, p.247), a percepção dos profissionais enfermeiros e médicos da estratégia Saúde da Família (ESF) de Porto Velho/RO com relação ao trabalho dos profissionais de Educação Física vinculados ao NASF está representada, principalmente, pela "amenização dos efeitos de doenças crônico-degenerativas (como hipertensão e diabetes)". Os autores chamam atenção para o desconhecimento dos profissionais sobre as políticas e programas nacionais de saúde, inclusive sobre a criação do NASF. 
Contribui para tal dificuldade, a interpretação desses profissionais de que o NASF atuaria, em última instância, junto a um grande contingente de usuários do SUS. Os autores analisaram que a portaria que criou o NASF (BRASIL, 2008) dá margem para essa interpretação dos profissionais. Nesse sentido, não é de se surpreender que muitos profissionais da ESF esperassem que a equipe NASF assumisse as demandas do território a partir das especialidades profissionais, reforçando os processos de encaminhamento e de ações curativas (PEDROSA; LEAL, 2012).

A publicação das Diretrizes do NASF parece estar suprindo em parte essa lacuna, pois identificamos trechos do referido texto com uma orientação muito clara de que o processo de trabalho dos profissionais do NASF deve ser desenvolvido por meio do apoio matricial, com espaços coletivos de discussões e planejamento (BRASIL, 2009). Contudo, essa orientação parece ter poucas repercussões na realidade de trabalho da maioria das equipes de ESF, exigindo dos profissionais do NASF uma leitura cuidadosa dos processos de trabalho das equipes e do território a fim de compreender as dificuldades e buscar seu enfretamento conjunto.

Em pesquisa realizada com profissionais de Educação Física que trabalham no NASF no norte do Paraná, foi verificado que a maioria dos profissionais trabalhava com grupos nas unidades de saúde e apenas um trabalhava oferecendo, exclusivamente, apoio às equipes de ESF. Esses profissionais davam suporte, em média, para cinco unidades de saúde fixas a partir de um trabalho por escala (SOUZA; LOCH, 2011). Com efeito, é possível que a maioria desses trabalhadores esteja assumindo diretamente os grupos das unidades de saúde, privilegiando na organização do processo de trabalho as ações específicas do campo profissional. Com a demanda elevada de usuários por unidade de saúde, provavelmente, o trabalho coletivo de planejamento e avaliações das ações com a equipe NASF, bem como com as equipes de ESF, pode estar comprometido provocando ações cada vez mais isoladas.

Observou-se, também, que os profissionais de Educação Física do NASF de Londrina/PR realizavam um trabalho, na maioria das vezes, com pouca integração com as equipes de Saúde da Família. O autor argumenta a necessidade de formação permanente no próprio trabalho e da mudança da concepção curativa das equipes de Saúde da Família. Também relataram dificuldades para utilização de salas, materiais e veículos da unidade de saúde (MENDONÇA, 2012). De forma similar, os profissionais de Educação Física do NASF do norte do Paraná também mencionaram como principal dificuldade do trabalho, a falta de espaço físico para desenvolvimento das atividades (SOUZA; LOCH, 2011).

Nas "Diretrizes do NASF" identificou-se que a compreensão do eixo das Práticas Corporais/Atividade Física (PCAF) no contexto do SUS é ressignificada à luz da concepção de saúde como produção social. Com efeito, a demarcação conceitual e política expõe, nos parágrafos iniciais do documento, os desafios para o campo da Educação Física em integrar uma equipe multiprofissional a partir dessa perspectiva. Um trecho do documento ressalta os conceitos mencionados:

(...) entendendo a produção da saúde como resultante dos determinantes e condicionantes sociais da vida, é que o eixo das PCAF, nos termos previstos na 
PNPS [Política Nacional de Promoção da Saúde] se ressignifica, vislumbrando novas possibilidades de organização e de manifestação (BRASIL, 2009, p.144).

Também é importante lembrar que a concepção de saúde como produção social aparece na PNPS em 2006 e é reiterada neste documento em 2009, afirmando a complexidade do tema e, talvez, a dificuldade de apropriação dessa concepção nas práticas de saúde.

Outros aspectos conceituais são problematizados de forma crítica e contundente nas Diretrizes do NASF. Nestas Diretrizes, o conceito de "atividade física" é questionado como sinônimo de movimento, equiparação conceitual tradicional na saúde. Os autores do referido documento problematizam a limitação do termo ao enfocar apenas a dimensão fisiológica do ser humano, em geral, "biometricamente avaliado". Nesse sentido, acrescentam que "a concepção biológica de corpo parece não ser suficiente para responder às questões oriundas dos elementos determinantes da saúde [...]" (BRASIL, 2009, p.144). As questões conceituais e seus desdobramentos profissionais também vêm sendo pesquisadas e debatidas buscando superar alguns dos reducionismos presentes no campo acadêmico e a construção de novos consensos (LAZZAROTTI FILHO et al., 2010).

$\mathrm{Na}$ tentativa de superar os limites conceituais apresentados, identificou-se nas "Diretrizes do NASF" a apresentação de uma concepção de corpo no âmbito das PCAF:
O corpo cultural, repleto de símbolos e signos, que o torna único ao mesmo tempo em que Ihe inclui na identidade de um determinado grupo ou coletivo social, como bem define a Antropologia, que afirma não existir natureza humana independente da cultura (BRASIL, 2009, p.144).

Apesar das perspectivas progressistas indicadas nas políticas públicas brasileiras e nos marcos legais que tratam das PCAF, em uma investigação com profissionais de Educação Física do NASF de Londrina/PR, observou-se que suas concepções se sustentam a partir de uma visão comportamental e biológica do processo saúde-doença, na qual as mudanças passam invariavelmente pela responsabilidade individual dos sujeitos pela sua saúde (MENDONÇA, 2012).

Para o autor, o processo de trabalho do profissional de Educação Física no NASF reflete as dificuldades do processo formativo com ênfase, de forma geral, na dimensão biológica dos sujeitos em detrimentos de análises que considerem os aspectos filosóficos, históricos e sociais da relação entre atividade física e saúde. Na investigação com profissionais de Educação Física do NASF de Londrina/PR foi observado que a maioria das ações realizadas tem como objetivo o aprimoramento das capacidades físicas e a repetição dos movimentos, "sem que haja um espaço de criação, reflexão e contextualização das propostas" (MENDONÇA, 2012, p. 129).

5 Esse conceito é definido em sua acepção clássica como qualquer movimento produzido pela musculatura esquelética que produza gasto energético acima dos níveis de repouso, recomendação quase universalmente preconizada por diversas organizações, governos e centros de pesquisa (BRASIL, 2009). 
Além das atividades com grupos, os profissionais de Educação Física do NASF do norte do Paraná também realizavam "mini-palestras" sobre a "importância da prática da atividade física". Entre as atividades "prescritas" estão as atividades aeróbicas e os exercícios resistidos, em menor proporção atividades de alongamento, coordenação motora e atividades lúdicas, com uso de materiais alternativos como pesos com garrafa pet e cabo de vassouras. As atividades ocorriam de duas a três vezes por semana com aproximadamente uma hora de duração, sendo organizadas em partes, a saber: aquecimento, treinamento específico e relaxamento/alongamento. A maioria dos participantes era mulheres e idosos, usualmente com alguma patologia. Os autores chamam atenção para que o trabalho no NASF não tenha apenas um direcionamento "clínico", lembrando que as ações não devem privilegiar apenas populações adoecidas (SOUZA; LOCH, 2011, p. 8/9).

Em uma pesquisa realizada na Academia Carioca no município do Rio de Janeiro foi identificado que o profissional de Educação Física, no contexto da Atenção Básica, faz uso de protocolos médicos-centrados em uma abordagem biológica e medicalizada. Identificou-se a priorização dos atendimentos para grupos com hipertensão e diabetes, vinculados ao programa HIPERDIA. As dificuldades relatadas pelo profissional foram a grande demanda de trabalho e a falta de trabalhadores, as quais acarretaram "filas de espera" de usuários para participação nas atividades (XAVIER; ESPÍRITO-SANTO, 2011).

Pedrosa e Leal (2012) discutem que a inserção dos profissionais de Educação Física no serviço público de saúde não pode enfatizar somente o tratamento e a prevenção de doenças por meio da prática regular de exercícios físicos, mas deve prescindir do trabalho coletivo na elaboração de projetos com corresponsabilidades com as equipes de ESF no atendimento aos usuários.

Nas Diretrizes do NASF, os autores indicam como princípios que orientam a atuação profissional "a compreensão e contextualização histórica dos fenômenos, conceitos e determinações que envolvem a prática de atividade física na contemporaneidade [...] todas imbricadas nas relações sociais". Recomendam que os profissionais de Educação Física valorizem as manifestações da cultura corporal em um contexto de "formação crítica do sujeito, da família [...]", os quais possam superar o "aprisionamento técnico-pedagógico dos conteúdos clássicos da Educação Física" (BRASIL, 2009, p. 144).

Ações "tradicionais" do campo da Educação Física como "avaliação física e prescrição de exercícios" também foram mencionadas pontualmente no referido documento, desde que não provoquem "filas" e/ou não demandem a maior parte do tempo do profissional (BRASIL, 2009, p.149). Nota-se que este elemento representou uma das dificuldades relatadas pelo profissional da Academia Carioca. O enfoque dos autores das Diretrizes do NASF parece estar nas ações coletivas, com grupos e junto com a equipe multiprofissional do que em ações individuais, ainda que estas não sejam descartadas, mas avaliadas junto com as equipes de saúde da família.

Nessa trilha, os autores chamam atenção nas Diretrizes do NASF para a definição do público alvo ou prioridade das ações, a qual deve considerar a análise de saúde do território realizada de forma conjunta com a equipe NASF e da estratégia da 
Saúde da Família; a eleição de critérios que não excluam faixas etárias e/ou estigmatizem sujeitos por suas condições de saúde, por exemplo, diabéticos e/ou hipertensos; que favoreça o maior número de pessoas; que extrapolem os espaços de saúde, identificando lugares no território que expressem identidade do grupo e facilitem o acesso das pessoas às atividades. Neste contexto, destaca-se a relevância do planejamento participativo das ações, dentre as quais se podem considerar, os desejos e aspirações dos sujeitos, por meio de propostas de pertencimento coletivo e evitar imposição de ações/modelos (BRASIL, 2009).

No citado documento, o conceito de território é entendido como "elemento vivo e multidimensional, que deve ser captado e compreendido em todas as suas nuances" (BRASIL, 2009, p.151). Essa concepção foi muito difundida nos serviços públicos de saúde, em especial na Atenção Básica, apesar da compreensão limitada do conceito à dimensão gerencial e das dificuldades das equipes de saúde em concretizar processos de territorialização na realidade de trabaIho. Considerando esta limitação, talvez os profissionais do NASF possam colaborar em resgatar essa acepção ampliada, contribuindo para efetivar esse processo junto às equipes de ESF.

Avalia-se que há um especial desafio para a Educação Física em buscar integrar as ações no território com espaços já consolidados do esporte, lazer e da escola, assim como os projetos mais recentes como a Academia da Saúde e o Programa Saúde na Escola. Nas Diretrizes do NASF identificou-se o favorecimento de ações intersetoriais, em especial, articuladas aos programas e projetos federais de atividade física com foco em escolares com objetivo de evitar sobreposição de ações e potencializar as já existentes (BRASIL, 2009).

Nesse sentido, as "Diretrizes do NASF" apresentam reconhecimento da importância da promoção da saúde na construção das PCAF articulada na compreensão dos aspectos culturais, históricos, políticos, econômicos e sociais do "espaço-território", valorizando a realidade local como "princípios da atuação profissional do NASF" para a construção de ações em saúde, em especial das PCAF (BRASIL, 2009, p.145).

Há no mencionado documento, a reiterada alusão à promoção da saúde como perspectiva orientadora do trabalho a ser desenvolvido no NASF. Com efeito, os autores salientam a diferença entre promoção da saúde e prevenção de doenças, como se pode verificar no trecho abaixo:

promover significa fomentar, desenvolver algo que possibilite a escolha, a autonomia e a coresponsabilidade dos sujeitos envolvidos na construção coletiva de modos de viver melhor. Já a prevenção caracteriza-se por impedir que algo aconteça, não importando o momento (BRASIL, 2009, p.148).

Na pesquisa de Mendonça (2012, p.128) com profissionais de Educação Física que trabalham no NASF em Londrina/ PR, foi identificado que há uma confusão conceitual entre promoção da saúde e prevenção de doenças. Vários profissionais apresentaram um entendimento de promoção da saúde "com base na responsabilidade individual". O autor argumenta que esta concepção do processo saúde-doença está atrelada a disseminação dos estudos epidemiológicos e da concepção biológica deste processo. Com efeito, apenas um profissional, dos dez investigados, apresentou uma concepção de promoção da saúde 
considerada "ampliada", segundo o autor, a partir das definições ensejadas pela Carta de Ottawa.

Identificou-se nos estudos certa perspectiva comportamental e biologicista do processo saúde-doença relacionados à perspectiva de responsabilização individual pela saúde; ações que visavam ao aprimoramento das capacidades físicas e a repetição dos movimentos (MENDONÇA, 2012); uso de protocolos médicos-centrados em uma abordagem biológica e medicalizante; e a priorização de grupos por critérios como patologia ou ciclo de vida, por exemplo, hipertensos, diabéticos ou idosos (XAVIER; ESPÍRITO-SANTO, 2011).

Retomando à reflexão sobre a função social da Educação Física na Saúde Pública observou-se, a partir das pesquisas relatadas sobre a implantação do NASF e da análise das suas Diretrizes, que existem outros elementos importantes da realidade concreta de trabalho que devem ser considerados na questão anunciada. Além dos aspectos vinculados à precarização e a flexibilização do trabalho, identificou-se a reprodução dos conceitos hegemônicos do modelo biomédico na maioria das equipes de Saúde da Família e também nos profissionais de Educação Física. Ora, como uma proposta considerada de mudança de modelo tecnoassistencial, como é o caso da estratégia Saúde da Família, irá se efetivar se os trabalhadores da saúde não tiverem uma formação sólida para compreender as relações sociais que determinam não só a condição de fragilidade da política social brasileira e o processo saúde-doença dos seres humanos, mas também de suas consciências sobre o mundo? Com efeito, tornam-se inócuas propostas que delegam exclusivamente aos próprios trabalhadores as mudanças necessárias. Na totalidade da realidade social, os trabalhadores possuem autonomia relativa para provocar mudanças no seu trabalho, pois os elementos fundantes do modo de produção capitalista - divisão social do trabalho e a propriedade privada dos meios de produção (NETTO; BRAZ, 2010) - mantêm-se intactos. Os profissionais de Educação Física, enquanto parte da classe trabalhadora, necessitam se apropriar desses conhecimentos para que seja possível ter uma ação crítica sobre o mundo, individual e coletivamente, compreendendo também seus próprios limites para desencadear processos emancipatórios na vigência do modo de produção capitalista.

Apesar da pequena quantidade de produções acadêmicas sobre o trabalho do profissional de Educação Física no NASF no país, observou-se que em todas as pesquisas encontradas há debate em torno da necessidade de mudanças na formação acadêmica para qualificar, de uma forma geral, o trabaIho na saúde pública, tema pouco abordado nos cursos de graduação (ANJOS: DUARTE, 2009; BRUGNEROTTO; SIMÕES, 2009).

Para Pedrosa e Leal (2012, p. 249), é necessária uma análise da qualidade da formação profissional para atender ao perfil exigido para atuação nas novas estratégias de ação para a promoção da saúde e da aproximação dos profissionais que já atuam no setor. $\mathrm{O}$ autor também chama atenção para necessidade de análises mais profundas sobre a "atuação prática" e do estímulo para participação em eventos do campo da saúde. Além disso, também problematiza as responsabilidades dos gestores em promover maior capacitação, informação e comunicação sobre políticas públicas de saúde.

De forma similar, Santos (2012) salienta que a Educação Física possui pouca 
"experiência prática" nos serviços públicos de saúde e enfrenta o desafio na definição do seu papel profissional e das competências necessárias para atuação junto ao SUS. A autora também contextualiza algumas iniciativas do governo federal, tais como o Programa Nacional de Reorientação da Formação Profissional em Saúde (PRO-SAÚDE) e o Programa de Educação pelo Trabalho em Saúde (Pet-Saúde), na indução de mudanças na formação, em nível de graduação e pós-graduação, dos cursos do campo da saúde, os quais devem atender às necessidades da população brasileira e do SUS.

Souza e Loch (2011, p.9), apesar de reconhecerem algumas mudanças na formação, atribuem algumas dificuldades relatadas pelos profissionais de Educação Física do NASF do norte do Paraná "a presença de currículos generalistas superficiais". Tais currículos, não sustentariam uma intervenção profissional sólida, pois formam "professores" para atuar na escola e "profissionais" para atuar fora deste ambiente. Com efeito, admitem que a formação para intervenção profissional na saúde pública ainda precisa ser consolidada e sugerem "a divisão entre licenciatura e bacharelado como uma alternativa para melhor caracterizar o campo de intervenção para cada habilitação".

Corroborando com Quint et al. (2005), Mendonça (2012) argumenta que os pressupostos da Saúde Coletiva e das teorias progressistas da Educação Física podem ampliar novos horizontes para o trato com o conhecimento e orientação da prática pedagógica em unidades de saúde da família.
O autor propõe que os conhecimentos da Saúde Coletiva precisam ser incorporados na graduação como tema "transversal com potencial transformador das práticas de educação física", não somente no formato de uma disciplina (MENDONÇA, 2012, p.130).

\section{A Educação Física no serviço público de Saúde de Goiânia}

De acordo com dados oficiais da Secretaria Municipal de Saúde de Goiânia, existem, atualmente, 30 profissionais de Educação Física contratados pela aludida Secretaria (SECRETARIA MUNICIPAL DE SAÚDE DE GOIÂNIA, 2012) no município. Praticamente um terço destes trabalhadores (21 profissionais) está vinculado aos serviços de saúde mental de Goiânia/GO, em especial nos diferentes Centros de Atenção Psicossocial (CAPS). Os outros trabalhadores estão vinculados a Distritos Sanitários, Centro de Atenção Integral à Saúde (CAIS) e ao Centro de Referência em Atenção à Saúde da Pessoa Idosa (CRASPI).

As primeiras contratações de profissionais de Educação Física no serviço público de saúde de Goiânia/GO datam de 2002 , com a entrada de quatro profissionais, segundo o documento analisado. Observa-se que desses quatro trabalhadores citados, dois possuem como cargo a denominação de "profissional de educação II", o qual se supõe o vínculo destes profissionais com a secretaria de educação e uma possível transferência para a secretaria da saúde. No total de profissionais contratados pela secretaria de saúde apenas dois trabalhadores possuem esse cargo, o restante (28) exerce o cargo de "analista em cultura e desportos" ${ }^{6}$,

6 Esses cargos não possuem correspondência com as possibilidades de registro da Educação Física segundo a Classificação Brasileira de Ocupações (CBO). 
com diferenças salariais importantes por conta dos diferentes cargos.

Em investigação realizada em 2009 com os profissionais que compuseram a equipe de implantação do NASF em Goiânia/GO, foi identificada que a representação que aquela equipe tinha sobre o trabalho do profissional de Educação Física indicava um duplo papel. A dupla representação consistia de um educador e de um profissional da saúde. Uma responsabilidade na orientação sobre a prática de exercícios físicos para as equipes de ESF e a população; e a contribuição na redução de doenças e agravos não transmissíveis (MARTINEZ; PELLIZZARO; SILVA, 2009).

Nesse aspecto, os sujeitos que construíram o projeto de implantação do NASF em Goiânia argumentaram que a opção por esse profissional decorreu da compreensão de que é um profissional da saúde e da educação, transitando em ambas as áreas, o que o aproxima do modelo de ação do NASF. Além disso, nessa mesma pesquisa (MARTINEZ; PELLIZZARO; SILVA, 2009) a equipe de implantação do NASF argumentou da importância das ações com as PCAF num conjunto grande de doenças não transmissíveis, justificando a importância desse profissional na equipe multidisciplinar.

Em Goiânia/GO, o NASF foi implantado apenas na região noroeste, a qual conta com quatro professores de Educação Física trabalhando nos serviços públicos de saúde. Desses, três estão vinculados ao NASF e um ao CAIS Cândida de Moraes. Os três professores que estão trabalhando no NASF possuem lotação no Distrito Sanitário Noroeste, conforme o documento citado acima. Dois deles exercem o cargo de "analista em cultura e desportos" e um de "profissional de educação II". Como o processo seletivo dos profissionais do NASF ocorreu "internamente", os atuais vínculos profissionais se mantiveram produzindo desigualdades salariais importantes.

Em pesquisa recente, MARTINEZ (2014) observou que na identificação do perfil sócio-profissional dos trabalhadores do NASF os profissionais de Educação Física são aqueles com salários mais baixos da equipe multidisciplinar, inclusive com importantes desigualdades entre eles. A mesma pesquisa identificou que as diferenças salariais entre os profissionais podem ser compreendidas pela impossibilidade do recebimento da gratificação, pois um dos professores manteve vínculo empregatício com a Secretaria de Educação mesmo trabalhando na saúde.

Ainda que pesem essas desigualdades, a contratação efetiva dos profissionais do NASF de Goiânia garante trabalho com mais estabilidade e qualidade do que outros estudos relataram. Esta condição de trabaIho não está dada a outros profissionais de Educação Física em outros NASFs do país, os quais estão submetidos a processos de precarização e flexibilização dos contratos, em especial, a partir das Organizações Sociais, conforme mencionamos acima.

Nesse estudo citado, identificou-se que, antes da implantação do NASF, a ação mais comum desenvolvida nos serviços públicos de saúde da região noroeste era a atividade de "caminhada com grupo". O trabalho estava centrado no apoio a grupos de caminhada e educativos, principalmente, àqueles dirigidos a pessoas com obesidade e/ou hipertensão e diabetes em projeto conhecido como "HIPERDIA". Na região, porém, encontram-se outros equipamentos de lazer que desenvolvem ações relativas à Educação Física como Clube do Povo, 
ligado à Secretaria de Esporte e Lazer, e o Centro de Referência em Assistência Social (CRAS), os quais possuem profissional de Educação Física atuando regularmente. Martinez (2014) menciona que com o trabalho do NASF na região houve projetos de território com trabalhadores da ESF e adolescentes, além da previsão de ações no programa Academia da Saúde em processo de implantação no município. O estudo destaca, ainda, por parte de outros membros da equipe multidisciplinar e da gestão do NASF uma valoração muito positiva aos profissionais de Educação Física na participação no processo de implantação, construção da dinâmica de trabalho e encaminhamento das demandas provenientes de todo serviço público da região.

Nesse contexto, parece importante problematizar que o trabalho com grupos já constitui como prática de alguns profissionais de Educação Física do NASF no país, de acordo com os estudos apresentados. Observou-se, contudo, uma tendência nesse trabalho que indica uma priorização da especificidade profissional, exemplificada pela investigação com profissionais do norte do Paraná (SOUZA; LOCH, 2011) que pode estar desarticulada da reflexão e do planejamento coletivo do trabalho. Assumir os grupos nas unidades de saúde pode gerar um trabalho isolado do profissional de Educação Física, desintegrado do trabalho, dos projetos da equipe NASF e do trabalho conjunto com as equipes de Saúde da Família.

\section{CONSIDERAÇÕES FINAIS}

Os dados apontam uma diversidade muito grande de denominações que fazem referência ao mesmo profissional de Educação Física no âmbito da saúde, o que indica uma fraca consolidação dos conceitos (BOURDIEU, 2011), característica de um campo ainda recente, especialmente no que se refere à sua inserção no serviço público de saúde.

As Diretrizes do NASF orientam critérios para definição do público alvo das atividades que não devem prescindir da análise do território; da localização de espaços comunitários onde já ocorram atividades ou que possam ser utilizados para esse fim; da identificação e compreensão das manifestações da cultura corporal presentes no grupo social característico do território. Além disso, é necessário superar práticas conservadoras que não garantem a participação dos sujeitos na construção, planejamento e avaliação das propostas, como salientam vários autores com contribuições importantes no campo da saúde pública (VASCONCELOS, 2007; STOTZ, 2007).

Identificou-se nos estudos sobre a Educação Física no NASF em diferentes regiões do país uma compreensão do processo saúde-doença com predomínio biologicista, uma responsabilização individual pela saúde e uma ênfase em ações que visavam ao aprimoramento das capacidades físicas e à repetição dos movimentos. O uso de protocolos médicos-centrados foi frequente, assim como, a priorização de grupos por critérios como patologia ou idade. Nessa questão, Goiânia difere dos demais relatos encontrados, buscando constituir suas referências de trabalho no âmbito da Saúde Coletiva, com participação efetiva e qualificada em todo o trabalho da equipe multidisciplinar desde sua implantação até o enfrentamento das demandas cotidianas.

É comum entre todos esses estudos relatados, indicações de forte precarização 
do trabalho profissional em Educação Física com pouca estabilidade de emprego, dupla jornada de trabalho e remuneração abaixo dos demais profissionais que compõem as equipes multidisciplinares em saúde. Dado importante, que precisa ser adequadamente enfrentado, sobretudo pelo poder público, em busca pela dignidade do trabalho e oferta de serviço qualificado e competente à população brasileira.

\section{REFERÊNCIAS}

ANJOS, T; DUARTE, A. C. G. O. Educação Física e a Estratégia Saúde da Família: Formação e atuação profissional. Physis, Rio de Janeiro, v. 19, n. 4, p. 11271144, 2009.

BOURDIEU, P. Homo academicus. Florianópolis: Ed. da UFSC, 2011.

BRASIL. Ministério da Saúde. Portaria n ${ }^{\circ} 154$ de 24 de janeiro de 2008 cria os Núcleos de Apoio à Saúde da Família - NASF. Brasília: Ministério da Saúde, 2008. Ministério da Saúde. Secretaria de Atenção à Saúde. Departamento de Atenção Básica. Diretrizes do NASF. Brasília: Ministério da Saúde, 2009. - Ministério da Saúde. Portaria $\mathrm{n}^{\circ} 3124$ de 28 de dezembro de 2012 redefini os parâmetros de vinculação dos Núcleos de Apoio à Saúde da Família (NASF) modalidades 1 e 2 às equipes de Saúde da Família ou equipes de Atenção Básica para populações específicas, cria a modalidade NASF 3, e dá outras providências. Brasília: Ministério da Saúde, 2012.

BRUGNEROTTO, F.; SIMÕES, R. Caracterização dos currículos de formação profissional em Educação Física: um enfoque sobre saúde. Physis, Rio de Janeiro, v. 19, n. 1, p. 149-172, 2009.
BUENO, A. X. Entre o fazer e o registrar da Educação Física no NASF: a relação conflitante entre a Classificação Brasileira de Ocupações e os procedimentos possíveis de registro pelo profissional de Educação Física. 106f. Dissertação (Mestrado em Ciências do Movimento Humano) - Programa de Pós-graduação em Ciências do Movimento Humano, Universidade Federal do Rio Grande do Sul, [2012].

LAZZAROTTI FILHO, A. et al. O termo práticas corporais na literatura científica brasileira e sua repercussão no campo da Educação Física. Movimento, Porto Alegre, v. 16, n. 1, p. 11-29, jan./ mar., 2010.Disponível em http:// seer.ufrgs.br/index.php/Movimento/ article/view/9000/7513. Acesso em 13/02/2014.

MARTINEZ, J.F.N. Educação Física e Saúde Pública: a inserção do profissional de Educação Física em um Núcleo de Apoio à Saúde da Família (Goiânia/ GO). Tese (Doutorado em Ciências da Saúde) - Programa de Pós-graduação em Ciências da Saúde, Universidade Federal de Goiás, [2014].

MENDONÇA, A. M. Promoção da saúde e processo de trabalho dos profissionais de Educação Física nos Núcleos de Apoio à Saúde da Família - NASF. Dissertação (Mestrado em Saúde Coletiva) - Programa de Pós-graduação em Saúde Coletiva, Universidade Estadual de Londrina, [2012].

MINAYO, M.C.S. O desafio do conhecimento: pesquisa qualitativa em saúde. 12. ed. São Paulo: Hucitec, 2010. NETTO, J. P.; BRAZ, M. Economia Política: uma introdução crítica. 6. ed. São Paulo: Cortez, 2010. 
PEDROSA, O. P.; LEAL, A. F. A inserção do profissional de Educação Física na estratégia Saúde da Família em uma capital do norte do Brasil. Movimento, v.18, n.2, p. 235-253, abr./jun., 2012.

PINTO, E. G. Organizações Sociais e Reforma do Estado no Brasil: riscos e desafios nesta forma de institucionalizar a parceria Estado-Sociedade Organizada. In: XIV CONCURSO DE ENSAYOS DEL CLAD "ADMINISTRACIÓN PÚBLICA Y CIUDADANÍA". Anais... XIV Concurso de Ensayos del CLAD "Administración Pública y Ciudadanía". Caracas/ Venezuela; CLAD, 2000.

QUINT, F. O. et al. Reflexões sobre a inserção da Educação Física no Programa Saúde da Família. Motrivivência, Florianópolis, v. 17, n. 24, p. 81-95, jun., 2005.

SECRETARIA MUNICIPAL DE SAÚDE. Departamento de Gestão do Trabalho e Educação. Documento com a relação da quantidade de profissionais, cargo, atual lotação, data de ingresso no serviço e situação funcional. Goiânia, 2012 (mimeo).

SANTOS, S. F. S. Núcleo de Apoio à Saúde da Família no Brasil e a atuação do profissional de Educação Física. $185 f$. Dissertação (Mestrado em Educação Física) - Programa de Pós-graduação em
Educação Física, Universidade Federal de Santa Catarina, [2012].

SOUZA, S. C.; LOCH, M. R. A intervenção do profissional de educação física nos Núcleos de Apoio à Saúde da Família dos municípios do norte do Paraná. Revista Brasileira de Atividade Física e Saúde, v.16, n.1, p. 5-10, 2011.

STOTZ, E. Enfoques sobre educação popular e saúde. In: BRASIL. Ministério da Saúde. Secretaria de Gestão Estratégica e Participativa. Caderno de Educação Popular e Saúde. Brasília: Ministério da Saúde, 2007. p.46-57.

VASCONCELOS, E. M. Educação Popular: um instrumento de gestão participativa dos serviços de saúde. In: BRASIL. Ministério da Saúde. Secretaria de Gestão Estratégica e Participativa. Caderno de Educação Popular e Saúde. Brasília: Ministério da Saúde, 2007. p.18-30.

XAVIER, P.; ESPÍRITO-SANTO; G.. O trabalho do profissional de Educação Física no NASF: um estudo de caso. In: CONGRESSO BRASILEIRO DE CIÊNCIAS DO ESPORTE, 17., 2011, Porto Alegre./CONGRESSO INTERNACIONAL DE CIÊNCIAS DO ESPORTE, 4., 2011, Porto Alegre. Anais... Porto Alegre: UFRGS: CBCE, 2011. 1 CD-ROM. 
V. $26, \mathrm{n}^{\circ} 42$, junho/2014

THE GUIDELINES OF THE NASF AND THE PRESENCE OF THE PHYSICAL EDUCATION PROFESSIONAL

\begin{abstract}
The aim of the article is talk about the participation of professional in Physical Education at the Center for Health Care of the Family (NASF) program, focus on the city of Goiania (Brazil). The method of study was a literature and document review. The results indicated that $49.2 \%$ of the NASF teams in Brazil with the participation of a professional physical education, however there is a diversity of denominations for professional. In Goiania (Brazil) it was observed that working professionals receive less pay than other professionals in the multidisciplinary team, despite having a very positive evaluation of his work by other professionals, as well as management.
\end{abstract}

Key-words: Public Health; Center for Health Care of the Family; Physical Education.

Recebido em: fevereiro/2014

Aprovado em: junho/2014 